\title{
Morphological study of the field-aligned E-layer irregularities observed by the Gadanki VHF radar
}

\author{
C. J. $\operatorname{Pan}^{1}$ and P. B. Rao ${ }^{2}$ \\ ${ }^{1}$ Institute of Space Science, National Central University, Chung-Li, 32054, Taiwan \\ ${ }^{2}$ National Remote Sensing Agency, Balanagar, Hyderabad 500 037, India
}

Received: 23 December 2003 - Revised: 31 May 2004 - Accepted: 9 June 2004 - Published: 29 November 2004

Part of Special Issue "10th International Workshop on Technical and Scientific Aspects of MST Radar (MST10)"

\begin{abstract}
We report on the field-aligned irregularities observed in the low-latitude sporadic E-layer (Es) with the Gadanki $\left(13.5^{\circ} \mathrm{N}, 79.2^{\circ} \mathrm{E}\right.$; geomagnetic latitude $\left.6.3^{\circ} \mathrm{N}\right)$ VHF radar. The radar was operated intermittently for 15 days during the summer months in 1998 and 1999, for both daytime and nighttime observation. The total observation periods are $161 \mathrm{~h}$ for the nighttime and $68 \mathrm{~h}$ for the daytime. The observations were used to study the percentage of occurrence of the E-region echoes for both daytime and nighttime. The statistical characteristics of the mean radial velocity and spectral width are presented for three cases based on the echo occurrence characteristics and the altitude of observations (from 90 to $140 \mathrm{~km}$ ranges), namely, the lower Eregion daytime $(90-110 \mathrm{~km})$, the lower E-region nighttime (90-105 km) and the upper E-region nighttime (105-140 km) echoes. The results are compared with that of Piura, a lowlatitude station located at about the same geomagnetic latitude, but to the south of the equator. By comparing the behaviors of the lower E-region radar echoes of the summer months between Gadanki and Piura, we find that the lower altitude echoes below about $100 \mathrm{~km}$ are rarely reported in Piura but commonly seen in Gadanki. Features of the nighttime echoes observed by these two radars are quite similar but daytime FAI echoes are again seldom detected by Piura.
\end{abstract}

Key words. Ionosphere (ionospheric irregularities) - Radio science (remote sensing, ionospheric physics, instruments and techniques)

\section{Introduction}

An interesting investigation of the field-aligned irregularities (FAI) in the nighttime sporadic-E-layers reported by Yamamoto et al. (1991) with the MU radar $\left(34.9^{\circ} \mathrm{N}, 136.1^{\circ} \mathrm{E}\right)$ in Japan has revealed one of the most important features in the mid-latitude ionosphere. By operating the radar with

Correspondence to: C. J. Pan

(cjpan@jupiter.ss.ncu.edu.tw) 600-m range resolution, they found that the FAI displayed different morphologies when viewed in height-time-intensity plots. "Quasi-periodic" (QP) echoes were found to occur during the post-sunset period while "continuous" echoes were found to occur in the post-sunrise period. Recent reports, however, show that the continuous echoes can occur throughout the whole night and not just in the post-sunrise period only (Ogawa et al., 1995, 2002; Patra and Rao, 1999; Choudhary and Mahajan, 1999).

There are some explanations for the QP echoes that have so far been proposed to account for these interesting observations. The first one from Woodman et al. (1991) suggested that existing sporadic E- (Es-) layers could be modulated in altitude by a passing atmospheric gravity wave (AGW) through ion drag along geomagnetic field lines. The second was proposed by Tsunoda et al. (1994) and relied on the electric field and polarization effects. More recently, Larsen (2000) proposed neutral wind shear instability to explain the spatial and temporal periodicities associated with QP echoes. Large wind shear crossing the threshold for shear instability and the resulting Kelvin-Helmholtz billows could well be the source of the ionospheric structure manifested as QP echoes. An intensive effort to obtain more detailed information associated with sporadic E-layer and QP structures was the Sporadic E Experiment over Kyushu (SEEK) carried out in southern Japan in 1996 (see Fukao et al., 1998, and other papers in that issue). The SEEK II campaign was also carried out in the summer of 2002 as a follow-up to the successful SEEK campaign. More extensive observational programs have now shown a broad range of QP structures in the Asian (Ogawa et al., 1995, 2002; Pan and Tsunoda, 1999; Patra and Rao, 1999; Pan and Larsen, 2000; Patra et al., 2002a, b) and European sectors (Haldoupis and Schlegel, 1996), and at several locations in the American sector (Chau and Woodman, 1999; Tsunoda et al., 1999; Hysell and Burcham, 1999, 2000; Chau et al., 2002).

In contrast to the QP radar echoes, the continuous echoes first reported by Yamamoto et al. (1991) seem not to have drawn much attention in the community. A study on the "non 


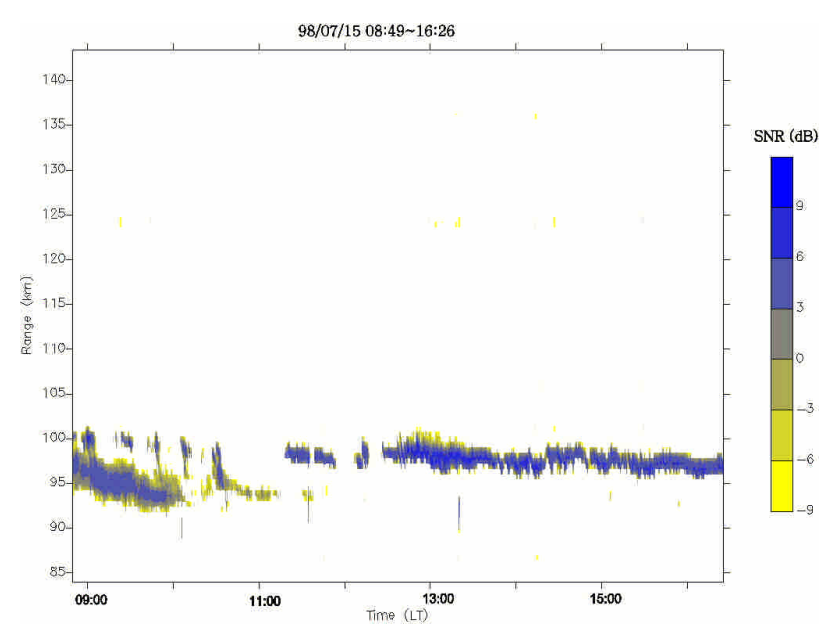

and Rao, 1999, 2002; Patra et al., 2002a, b). Moreover, given the similar dip angles over the Gadanki/India radar and the Piura/Peru radar (Chau and Woodman, 1999; Woodman et al., 1999; Chau et al., 2002), it provides an opportunity to compare two low-latitude stations located at about the same geomagnetic latitude, but on either side of the geographic equator.

\section{Experimental setup and data processing}

The MST radar at Gadanki is a coherent pulse Doppler radar operating at $53 \mathrm{MHz}$ with a peak power aperture product of $3 \times 10^{10} \mathrm{Wm}^{2}$. The antenna system occupying an area of $130 \mathrm{~m} \times 130 \mathrm{~m}$ is a phased array of $32 \times 32$ three element Yagi antennas consisting of two orthogonal sets, one for each polarization (magnetic EW and NS). It generates a radiation pattern with a main beam of $2.8^{\circ}$ (half-power full-width), a gain of $36 \mathrm{~dB}$ and a first sidelobe level of $-20 \mathrm{~dB}$. The main beam can be positioned at any look angle within $\pm 20^{\circ}$ off zenith in two principal planes. A detailed description of the Gadanki radar can be found in Rao et al. (1995).

We operated the radar on the nights (18:00 to 06:00 LT) of 17-20 June, 15-18 July, and 19-22 August during 1998; on the nights of 5-12 August and 16-19 August during 1999. On the other hand, daytime (09:00 to 18:00 LT) observations were carried out on 15-18 June, 13-16 July, and 17-20 August during 1998.

The magnetic declination of Gadanki is $2^{\circ}$ west of north. The antenna array is aligned along the geomagnetic northsouth direction, to enable ionospheric FAI studies by pointing the beam perpendicular to the field in the magnetic meridian plane. To detect the coherent backscatter from the Eregion irregularities, the radar beam is oriented at $13.2^{\circ}$ zenith angle due magnetic north, which satisfies the field perpendicularity condition at that height region. The observation range was from 90 to $140 \mathrm{~km}$ to cover the interesting low altitude QP (LQP) echoes and the normal QP echoes at higher altitudes. The range resolution is $600 \mathrm{~m}$, the time resolution is $15 \mathrm{~s}$ ( $2.5 \mathrm{~s}$ for single spectrum including processing time), the Doppler velocity window extends over -354 to $354 \mathrm{~m} / \mathrm{s}$ and its resolution is $5.5 \mathrm{~m} / \mathrm{s}$. The spectral moments, providing information on the total signal power, weighted mean Doppler velocity and spectral width, are computed using the expressions given by Woodman (1985).

\section{Data presentation}

al. (2000) did a case study and showed that the thermal instability mechanism proposed by Kagan and Kelly (2000) may provide a consistent explanation for the continuous echoes. Further, it has been shown that a neutral wind acting in a proper sense may assist the electric field in producing irregularities that are associated with the continuous echoes (Kagan, 2002).

We present the characteristics of the FAI radar echoes observed over Gadanki, India, which is the southern-most station, for the QP echo studies in the Asian sector (Krishna Murthy et al., 1998; Choudhary and Mahajan; 1999; Patra

By summarizing the main results of the earlier observations by the Gadanki radar we find that: (1) QP echoes appeared during most of the nighttime from altitudes between 102 and $116 \mathrm{~km},(2)$ the Low-altitude QP (LQP) echoes occurred both during daytime and nighttime and are confined to a slowly descending layer with a thickness of about $2-4 \mathrm{~km}$ in the height range of $90-100 \mathrm{~km}$, and (3) two to three layered structures of continuous nature existed during both daytime and nighttime (Krishna Murthy et al., 1998; Choudhary and 


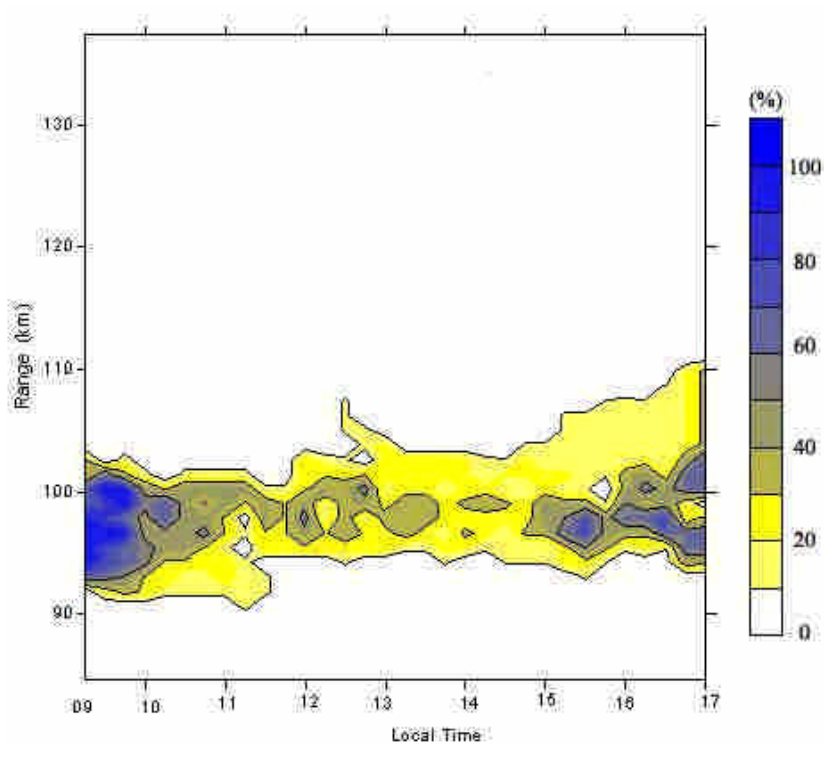

Fig. 2. The occurrence percentage of the daytime (09:00-18:00 LT) E-region FAI echoes with a minimum of $-6 \mathrm{~dB}$ SNR level and $15 \mathrm{~min} \times 1.2 \mathrm{~km}$ time-range resolution bin.

Mahajan; 1999; Patra and Rao, 1999; Pan and Rao; 2002; Patra et al., 2002a, b).

To show the morphological characteristics of the fieldaligned E-layer irregularities over Gadanki, we present statistical results of the radar echoes obtained with a 15-day data set gathered in 1998 and 1999. Observations have been made for both daytime (09:00 to 18:00 LT), as well as nighttime (18:00 to 06:00 LT), and the results are presented from a statistical study.

Figure 1 shows the range-time signal-to-noise ratio (SNR) values obtained from the daytime lower E-region irregularities observed on 15 July 1998 (upper panel) and from the nighttime irregularities on 17 July 1998 (lower panel). In this particular example, both types of E-region echoes, namely, QP and continuous types of echoes are noted. For the daytime echoes, the continuous type lower E-region echoes, centered at the range of about $95 \mathrm{~km}$, from 08:50 to 10:00 LT, are seen. On the other hand, QP type E-region echoes are observed at about 98 to $100 \mathrm{~km}$ range.

For the nighttime E-region echoes, similar features as those presented by Krishna Murthy et al. (1998), Choudhary and Mahajan (1999) and Patra and Rao (1999) are found. Most of the QP radar echoes are centered at about the $110-115 \mathrm{~km}$ range. Lower altitude QP radar echoes are found at ranges below $100 \mathrm{~km}$ (Urbina et al., 2000; Pan and Rao, 2002). Continuous types of echoes are found from 24:00 to 03:00 LT at ranges between 95 and $115 \mathrm{~km}$ in a descending trend. Those continuous echoes observed at this region show type-II echo features from the spectral analysis which are suggested to have been caused by the gradientdrift instabilities (Yamamoto et al., 1991; Ogawa et al., 1995; 2002; Choudhary and Mahajan, 1999). Recently, an alternative mechanism is proposed by Kagan and Kelly (2000)

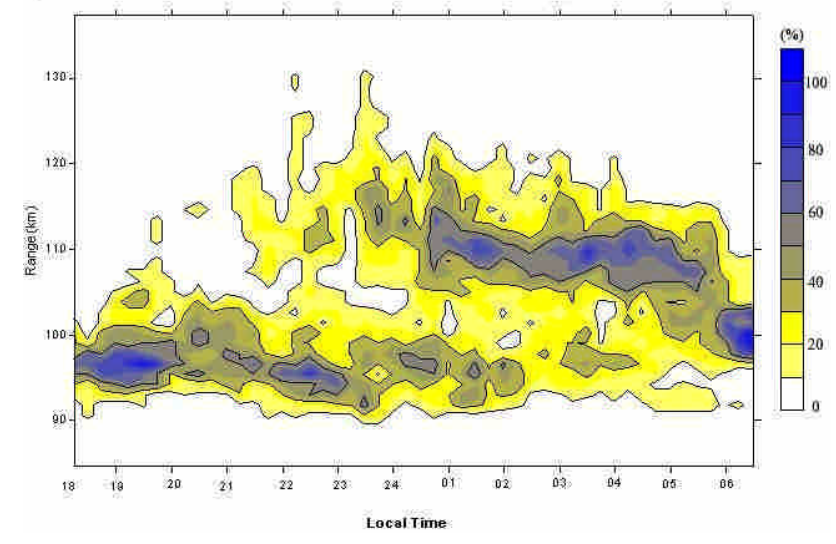

Fig. 3. The occurrence percentage of the nighttime (18:00 to 06:00 LT) E-region FAI echoes with a minimum of $-6 \mathrm{~dB}$ SNR level and $15 \mathrm{~min} \times 1.2 \mathrm{~km}$ time-range resolution bin.

and Kagan (2002) that type-II echoes may also be associated with thermal instability. For this 15-day data set, continuous echoes occurred frequently with the form of a descending multi-layer.

By using the range-time SNR plot of the 15-day data set, after removing the short-lived (few seconds at fixed ranges) meteor echoes manually, the information of the percentage of occurrence is derived. Figures 2 and 3 show the percentage of occurrence of E-region FAI echoes for daytime and nighttime, respectively. The threshold value of the signalto-noise ratio is $-6 \mathrm{~dB}$. To make the statistical results more smooth, but without losing the general features, the outputs of the range-time signal-to-noise ratio are further averaged to make the $15 \mathrm{~min} \times 1.2 \mathrm{~km}$ time-range resolution bin.

Since the continuous and QP echoes are present simultaneously and become mixed in different ranges in the day-today observations, we do not distinguish them in the occurrence statistics given in Figs. 2 and 3. As we can see from Fig. 2, most of the daytime E-region echoes appear at the ranges below $105 \mathrm{~km}$ and there is no echo detected above the range of $110 \mathrm{~km}$. Since these irregularities present the QP (the so-called LQP echoes) and the continuous features, we further separate them into two categories. For the daytime LQP echoes, the percentage of occurrence is about $70 \%$, where $63 \%$ of them occurred at the ranges between 98 and $100 \mathrm{~km}$ and $34 \%$ at 95 to $97 \mathrm{~km}$ range. The periods of the daytime LQP echoes are confined to the range of 1 to $5 \mathrm{~min}$ with dominant occurrence around $2 \mathrm{~min}$. Both the QP and continuous echoes are confined in the layered structures that are almost horizontally stratified. By examining Figure 2, we find that the occurrences of the noontime (11:00 to 14:00 LT) E-region echoes are less than at the other times, and based on the 15 days of statistics the daytime LQP echoes are found to be a rather common phenomenon.

Figure 3 is the percentage of occurrence of the nighttime E-region FAI echoes during the 18:00 to 06:00 LT period. We notice that there are two regions with significant occurrence 

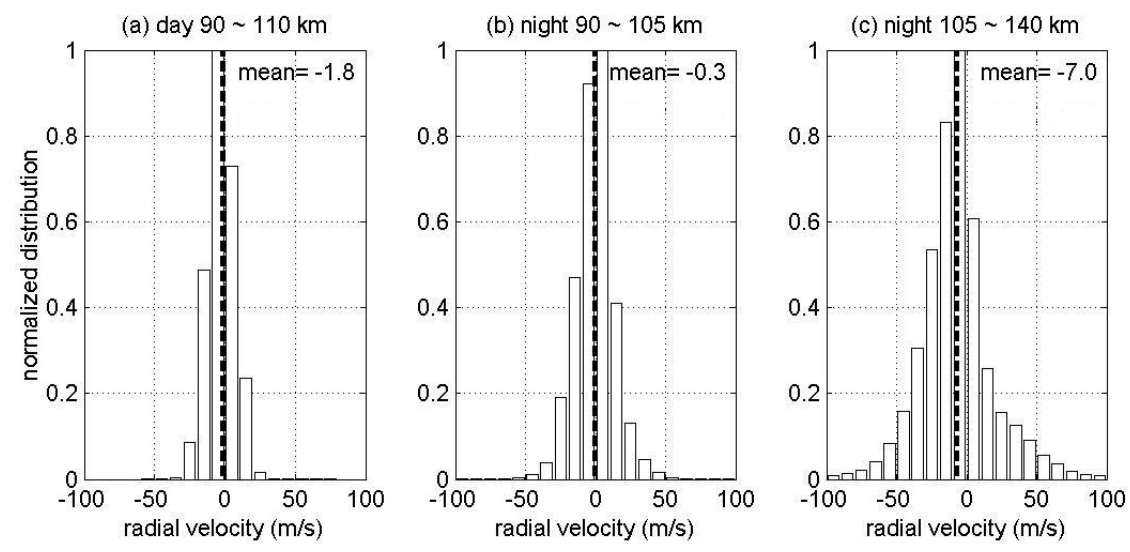

Fig. 4. The histograms of the mean radial velocity of the echoes for three categories: (left) daytime FAI echoes at 90-110 km range, (central) nighttime FAI echoes at 90 to $105 \mathrm{~km}$ range, and (right) nighttime FAI echoes at 105 to $140 \mathrm{~km}$ range.

percentage: one below the $105 \mathrm{~km}$ range that is similar to the daytime echoes and the other between 105 to $120 \mathrm{~km}$ ranges. By examining the range-time SNR plot of the 15-day data set (not shown here), we find that more than $90 \%$ of the upper region (105 to $120 \mathrm{~km}$ ranges) echoes are continuous type echoes, since no periodical feature can be discerned from the layered structures. While less than $10 \%$ of the echoes present QP features, the spectral characteristics of the QP echoes observed in the upper region are similar to those observed by other radars (Yamamoto et al, 1991; Pan and Tsunoda, 1999; Tsunoda et al., 1999). The maximum occurrence time interval of these nighttime FAI echoes is between 23:00 and 05:00 LT. The SNR values of the nighttime echoes are not much different from that of the daytime, being less only by about 1 to $2 \mathrm{~dB}$.

The lower region (below about $105 \mathrm{~km}$ range) echoes consist of QP (known as LQP) and continuous features just like those observed in the daytime echoes. We find that $45 \%$ of the observed echoes are characterized by QP features that correspond to the nighttime LQP echoes (Pan and Rao, 2002). The occurrence ranges of the nighttime LQP echoes are slightly lower than that of the daytime LQP echoes. We note that $57 \%$ of them appeared between 95 and $97 \mathrm{~km}, 24 \%$ between 92 and $94 \mathrm{~km}$ and $13 \%$ occurred at other ranges. The periodicities are similar to those of the daytime LQP echoes and the majority of them are found to be around $2 \mathrm{~min}$. Unlike the horizontally confined layers of the daytime LQP echoes, most of the nighttime LQP layers showed a significant descending rate of about $1.5 \mathrm{~km} / \mathrm{h}$.

Since the QP and the continuous types of echoes present Type II spectral features, we do not separately classify them in the following studies. Figure 4 presents the histograms of the mean radial velocity of the FAI echoes for three categories according to the observation ranges: (left) daytime echoes at $90-110 \mathrm{~km}$ range, (central) nighttime echoes at 90 to $105 \mathrm{~km}$ range, and (right) nighttime echoes at 105 to $140 \mathrm{~km}$ range. We notice from Fig. 4 that the ranges of values become wider as one moves from the left plot to the right plot. The mean radial velocities at the lower E-region vary between -30 and $+30 \mathrm{~m} / \mathrm{s}$ for daytime and -50 to $+50 \mathrm{~m} / \mathrm{s}$ during nighttime, and the values may vary from -100 to $+100 \mathrm{~m} / \mathrm{s}$ in the nighttime upper E-region. Furthermore, the mean radial velocities of the lower E-region echoes are close to zero for both daytime and nighttime but a small downward velocity is noticed in the upper E-region.

Figure 5 shows the histograms of the spectral widths for the same regions as in Fig. 4. It is clearly shown in Fig. 5 that the daytime and the nighttime echoes (for both upper and lower regions) present different distributions. The mean spectral widths in the daytime lower E-region present a bellshaped distribution with a mean value of about $30 \mathrm{~m} / \mathrm{s}$. On the other hand, nighttime echoes are asymmetric and are wider than those detected in the daytime. The majority of the spectral widths in the lower region are narrower (about 50 to $60 \mathrm{~m} / \mathrm{s}$ ) than that observed in the upper region (about $70 \mathrm{~m} / \mathrm{s})$.

\section{Summary and discussions}

Although the data collected by the Gadanki radar are limited to the summer months and to the observation range of 90 to $140 \mathrm{~km}$ only, it is still interesting to compare the behaviors of the E-region radar echoes between Gadanki and Piura (Chau and Woodman, 1999; Woodman et al., 1999; Chau et al., 2002). Over all, the following characteristics of the E-region FAI observed by the Gadanki radar based on this data set are noted:

1. There are two echoing regions: the lower region between 90 and $100 \mathrm{~km}$ ranges and the upper region between 105 and $120 \mathrm{~km}$ ranges.

2. Echoes observed in both the upper and lower regions are similar to type 2 echoes reported by other radars in the mid-latitudes.

3. Echoes of the lower region may occur in daytime as well as in nighttime. Although there is an observation 

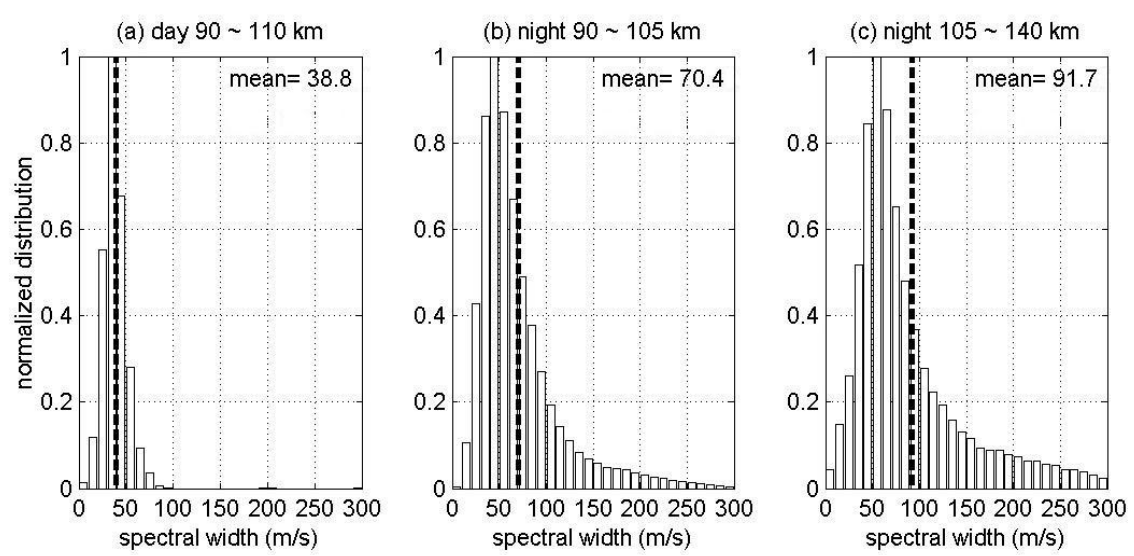

Fig. 5. The histograms of the spectral widths of the echoes for three categories: (left) daytime FAI echoes at 90-110 km range, (central) nighttime FAI echoes at 90 to $105 \mathrm{~km}$ range, and (right) nighttime FAI echoes at 105 to $140 \mathrm{~km}$ range.

break between 06:00 and 09:00 LT, noontime (11:00 to 14:00 LT) seems to be the minimum period of occurrence. The QP echoes that are commonly detected at the lower region, regardless of whether it is daytime or nighttime, are the so-called "LQP echoes".

4. The spectral characteristics of the lower region echoes differ from daytime to nighttime. The Doppler velocities are more variable and the spectral widths are broader and asymmetric in the nighttime in contrast to the daytime.

5. Unlike the values close to zero of the mean radial velocities of the lower E-region echoes, a small downward mean velocity is noticed in the upper E-region. Both the mean Doppler velocities and the spectral widths in the upper E-region are found to be larger than those of the lower E-region.

6. The upper region echoes appeared only in the nighttime with maximum occurrence between 23:00 and 05:00 LT. Typical QP echoes detected here are similar to those observed at mid-latitudes.

Chau and Woodman (1999) have studied the latitudinal differences of the QP echoes and Woodman et al. (1999) and Chau et al. (2002) presented the morphological features observed by the Piura radar. It is interesting to compare the longitudinal features of the FAI/QP echoes observed by the Gadanki and Piura radars. The geomagnetic latitudes of these two radars are $\sim 6.3^{\circ}$ and $\sim 7.5^{\circ}$ north, respectively, although the two systems are located on either side of the geographic equator. Both radars are pointing northward to be perpendicular to the geomagnetic field line $\left(12.5^{\circ}\right.$ and $13.9^{\circ}$ Dip angle, respectively) in the E-region at around $100 \mathrm{~km}$ altitude.

Here we compare the FAI/QP echo features reported by the Gadanki and Piura radars (Chau and Woodman, 1999; Woodman et al., 1999; Chau et al., 2002):
1. The percentage of occurrence of the nighttime echoes observed by the two radars is found to be quite similar.

2. Daytime FAI/LQP echoes are commonly present in the lower E-region at Gadanki, but have not been reported by Piura.

3. The spectral characteristics of the nighttime echoes are very similar, as seen by the two radars. It may also be noted that in the upper E-region both the radars observed a slightly downward mean radial velocity of about the same magnitude $(\sim 7 \mathrm{~m} / \mathrm{s})$.

4. The two radars commonly detect two to three thinlayered structures of 3-5 km thickness in the lower Eregion.

5. The QP echoes reported by the two radars are characterized by similar features as regard to periodicity, occurrence height and range rate, etc.

\section{Concluding remarks}

By using the 15-day data set gathered during the summers of 1998 and 1999, we present the morphological features of the E-region FAI observed by the Gadanki radar. We also compare the features of the FAI echoes observed by the Gadanki and Piura radars, since the geomagnetic latitudes of these two radars are close, even though they are located on either side of the geographic equator.

Although the general morphological features and spectral characteristics are very similar for the FAI echoes observed by the two radars, LQP echoes are rarely reported by the Piura radar, regardless of whether it is daytime or nighttime. Since the LQP echoes usually occur at altitudes below $100 \mathrm{~km}$, it is suggested that the neutral winds may play a role in the mechanism of their generation. The neutral wind fields associated with the atmospheric circulation would be distinctly different for Gadanki and Piura, the two stations having been located on opposite sides of the equator. It would, 
therefore, be quite interesting to take up a detailed study on how the neutral winds affect the E-region FAI in generating the LQP echoes, using coordinated radar observations over the two stations.

Acknowledgements. C. J. Pan was supported by the National Science Council of the Taiwan/R.O.C. through grant NSC 91-2811M008-0025 during the course of the study described here. The second author (P. B. Rao) acknowledges with thanks the fine facilities extended to him by the Director of the National Remote Sensing Agency, Hyderabad, India. The National MST Radar Facility (NMRF) is operated as an autonomous facility under Department of Space of the Indian government.

Topical Editor M. Lester thanks J. L. Chau and another referee for their help in evaluating this paper.

\section{References}

Chau, J. L. and Woodman, R. F.: Low-latitude QP echoes observed with the Piura VHF radar in the E-region, Geophys. Res. Lett., 26, 2167-2170, 1999.

Chau, J. L., Woodman, R. F., and Flores, L. A.: Statistical characteristics of low-latitude ionospheric field-aligned irregularities obtained with the Piura radar, Ann. Geophys., 1203-1212, 2002.

Choudhary, R. K. and Mahajan, K. K.: Tropical E-region field aligned irregularities: Simultaneous observations of continuous and QP echoes, J. Geophys. Res., 104, 2613-2619, 1999.

Fukao, S., Yamamoto, M., Tsunoda, R. T., Hayakawa, H., and Mukai, T.: The SEEK (Sporadic E Experiment over Kyushu) campaign, Geophys. Res. Lett, 25, 1761-1764, 1998.

Haldoupis, C. and Schelgel, K.: Characteristics of midlatitude coherent backscatter from ionospheric E-region obtained with Sporadic E scatter experiment, J. Geophys. Res., 101, 1338713 397, 1996.

Hysell, D. L. and Burcham, J. D.: HF radar observations of quasiperiodic E-layer echoes over North America, J. Geophys. Res., 104, 4361-4371, 1999.

Hysell, D. L. and Burcham, J. D.: The $30 \mathrm{MHz}$ radar interferometer studies of midlatitude E-region irregularities, J. Geophys. Res., 105, 12 797-12 812, 2000.

Kagan, L. M.: Effects of neutral gas motion on midlatitude E-region irregular structure, J. Atmos. S.-P., 64, 1479-1486, 2002.

Kagan, L. M. and Kelley, M. C.: A thermal mechanism for generation of small scale irregularities in the ionosphere E-region, J. Geophys. Res., 105, 5291-5303, 2000.

Kagan, L. M., Ogawa, T., Fukao, S., and Yamamoto, M.: A role of neutral motions in formation of midlatitude E-region fieldaligned irregularities, Geophys. Res. Lett, 27, 939-942, 2000.

Krishna Murthy, B. V., Ravindran, S., Viswanathan, K. S., Subbarao, K. S. V., Patra, A. K., and Rao, P. B.: Small-scale ( $3 \mathrm{~m})$ E-region irregularities at and off the magnetic equator, J. Geophys. Res., 103, 20 761-20 772, 1998.

Larsen, M. F.: A shear instability seeding mechanism for quasiperiodic radar echoes, J. Geophys. Res., 105, 24 931-24 940, 2000.

Lee, C. C., Liu, J. Y., and Pan, C. J.: The heights of Sporadic-Elayer simultaneously observed by the VHF radar and ionosondes in Chung-Li, Geophys. Res. Lett., 27, 641-644, 2000.
Ogawa, T., Yamamoto, M., and Fukao, S.: Middle and upper atmosphere radar observations of turbulence and movement of midlatitude sporadic E irregularities, J. Geophys. Res., 107, 12 173$12188,1995$.

Ogawa, T., Takahashi, O., Otsuka, Y., Nozaki, K., Yamamoto, M., and Kita, K.: Simultaneously middle and upper atmosphere radar and ionospheric sounder observations of midlatitude E-region irregularities and Sporadic E-layer, J. Geophys. Res., 100, 12751280, 2002.

Pan, C. J. and Tsunoda, R. T.: Semidiurnal behavior of quasiperiodic echoes in the mid-latitude Es-region observed with the Chung-Li VHF radar, Geophys. Res. Lett, 26, 2621-2624, 1999.

Pan, C. J. and Larsen, M. F.: Observations of QP radar echo structure consistent with neutral wind shear control of the initiation mechanism, Geophys. Res. Lett., 27, 867-870, 2000.

Pan, C. J. and Rao, P. B.: Low altitude quasi-periodic radar echoes observed by the Gadanki VHF radar, Geophys. Res. Lett., 29, 25-1, 2002.

Patra, A. K. and Rao, P. B.: High resolution radar measurements of turbulent structure in the low-latitude E-region, J. Geophys. Res., 104, 24 667-24 673, 1999.

Patra, A. K., Rao, P. B., Anandan, V. K., Jain, A. R., and Giswanathan, V.: Evidence of intermediate layer characteristics in the Gadanki radar observations of the upper E-region fieldaligned irregularities, Geophys. Res. Lett., 29, 41-1, 2002a.

Patra, A. K., Sripathi, S., siva Kumar, V., and Rao, P. B.: Evidence of kilometer-scale waves in the lower E-region from high resolution VHF radar observations over Gadanki, Geophys. Res. Lett., 29, 137-1, 2002b.

Rao, P. B., Jain, A. R., Kishore, P., Balamuralidhar, P., Damle, S. H., and Viswanathan, G.: Indian MST radar, 1, System description and sample wind measurements in ST mode, Radio Sci., 30, 1125-1138, 1995.

Tsunoda, R. T., Fukao, S., and Yamamoto, M.: On the origin of quasi-periodic radar backscatter from midlatitude sporadic E, Radio Sci., 29, 349-365, 1994.

Tsunoda, R. T., Yamamoto, M., Igarashi, K., Hoche, K., and Fukao, S.: Quasi-periodic radar echoes from midlatitude sporadic $\mathrm{E}$ and role of the 5-day plentary wave, Geophys. Res. Lett., 25, 951954, 1998.

Tsunoda, R. T., Buonocore, J. J., Saito, A., Kishimoto, T., Fukao, S., and Yamamoto, M.: First observations of quasi-periodic radar echoes from Stanford, California, Geophys. Res. Lett., 26, 995998, 1999.

Urbina, J., Kudeki, E., Franke, S. J., Gonzalez, S., Zhou, Q., and Collins, S. C.: $50 \mathrm{MHz}$ radar observations of mid-latitude Eregion irregularities at Camp Santiago, Puerto Rico, Geophys. Res. Lett., 27, 2853-2856, 2000.

Woodman, R. F.: Spectral moment estimation in MST radars, Radio Sci., 20, 1185-1195, 1985.

Woodman, R. F., Yamamoto, M., and Fukao, S.: Gravity wave modulations of gradient drift instabilities in midlatitude sporadic-E irregularities, Geophys. Res. Lett., 18, 1197-1200, 1991.

Woodman, R. F., Chau, J. L., and Aquino, F.: Low-latitude fieldaligned irregularitities observed in the E-region with the Piura VHF radar: First results, Radio Sci., 34, 983-990, 1999.

Yamamoto, M., Fukao, S., Woodman, R. F., Ogawa, T., Tsuda, T., and Kato, S.: Midlatitude E-region field aligned irregularities observed with the MU radar, J. Geophys. Res., 96, 15 943-15949, 1991. 